\section{Birlesik Dunya Arastrrma Cypriot Journal of Educational BD -CENTER \\ Sciences}

Innovasyon ve Yayıneılık Merkezi
Volume 16, Issue 3, (2021) 995-1009

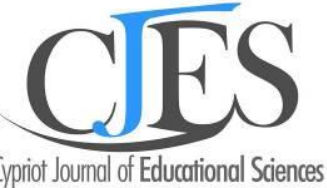

www.cjes.eu

\title{
Identification and analysis of core topics in educational artificial intelligence research: A Bibliometric analysis
}

Song $\mathbf{P u}^{\mathrm{a}}$, Faculty of Educational Studies, Universiti Putra Malaysia, Selangor, Malaysia and Guiyang Preschool Education College https://orcid.org/0000-0003-4997-9734

Nor Aniza Ahmad b 1 , Faculty of Educational Studies, Universiti Putra Malaysia, Selangor, Malaysia https://orcid.org/0000-0002-6230-3336

Mas Nida Md. Khambari c, Faculty of Educational Studies, Universiti Putra Malaysia, Selangor, Malaysia https://orcid.org/0000-0002-7517-9442

Ng Keng Yap d, Faculty of Computer Science and Information Technology, Universiti Putra Malaysia, Selangor, Malaysia

\section{Suggested Citation:}

Pu, S., Ahmad, M. N., Khambari, M. N. M., \& Yap, N. K., (2021). Identification and analysis of core topics in educational artificial intelligence research: A Bibliometric analysis. Cypriot Journal of Educational Science. 16(3), 995-1009 https://doi.org/10.18844/cjes.v16i3.5782

Received from December 15, 2020; revised from February 25, 2021; accepted from June 10, 2021. (C)2021 Birlesik Dunya Yenilik Arastirma ve Yayincilik Merkezi. All rights reserved.

\begin{abstract}
Educational artificial intelligence (EAI) means an integration of artificial intelligence (AI) and educational science that is going to serve as an authoritative element of the education system in the future. However, limited bibliographic analysis study have been carried out with the purpose of conceptualising the advancements in this field of educational billiography This study aim is to identify and analysis the core topics using keywords. The method of study is using the Keywords and cluster analysis by conducting a bibliometric review of 8,660 articles that have been published from 2000 to 2020 with the help of CiteSpace software. The results reveal that EAl research primarily encompasses three controversial topics. There is controversy about the Al application to students, Al does not replace teachers and Al algorithms have great contribution in the development of education sector. Study concluded that, Al applications can improve the effectiveness of students' learning, Al can replace part of the teachers' work, the relationship between the teacher and the machine should be cooperation, not the relationship between replacement and being replaced, under the premise that teachers give full play to their initiative and innovation.
\end{abstract}

Keywords: Educational artificial intelligence, core topics, Bibliometric analysis, CieSpace, Interactive learning environments

\footnotetext{
* ADDRESS FOR CORRESPONDENCE: Nor Aniza Ahmad, Faculty of Educational Studies, Universiti Putra Malaysia, Selangor, Malaysia

E-mail address: nor aniza@upm.edu.my
} 


\subsection{Introduction}

Convincing proof shows that artificial intelligence (AI) contributes to the sustainable development of education. According to Sales, (2019) jobs and everyday life problems will principally revolve around as it will be on the basis of intelligent production. Additionally, it may form part of a global sustainable development solution. In the last twenty years of technological advancement of big data and machine learning have remarkably impacted the development of Al technology in education field. Al has been considered in the education over the past three decades to solve the key issue such as create a system equally effectives like human to human tutoring (VanLehn, 2011). Contemporarily, the amalgamation of Al and education is currently an innovative research boom that is driven by national policies and the high demand for the education industry. In contrast to this background, some advancement has been made while summarising the literature on educational artificial intelligence (EAI). EAl symbolises using Al for supporting tailored, automated feedback and guidance taking place in the field of education. A variety of perspectives has been presented in these analyses, including the existing trends within the community of Al in education Kandlhofer et al., (2016) the evolution of the changing quality of interaction between students and teachers Guilherme (2017), Al in special education (Politis, Kyriafinis \& Aidona, 2018), trends and approach for intelligent tutoring system in a global context as well as past and present trends of intelligent tutoring systems (Han et al., 2019).

Educational artificial intelligence (EAI) refers to the use of artificial intelligence (AI) to support personalized and automated feedback and guidance in the educational field (Song \& Wang, 2020). In the past ten years of span the application of Artificial Intelligence (Al) has grown about $43 \%$ in higher education which has attracted researchers in the field of education (Roll \& Wylie 2016). Gigantic Tech companies such as Google have largely invested in the Al. Artificial Intelligence in education has open the new era for the universities such as Technical University of Eindhoven in the Netherlands has recently opened an Artificial Intelligence Systems Institute with fully trained professional staff for the education in Al (Zawacki-Richter et al., 2019). The growing use of $\mathrm{Al}$ in the education in 30 years and society of international artificial intelligence in education (IAIED) has launched in 1997 to encourage researchers to publish more studies in the EAI. Moreover, organized international seminars with the purpose to expend the knowledge of $\mathrm{Al}$ in education where more professionals in the education can be trained to support more student learning in the campus (Chen, Chen \& Lin, 2020) The use of Al in the education and research publications in the web of science and Google Scholar is shown in Figure 1. 


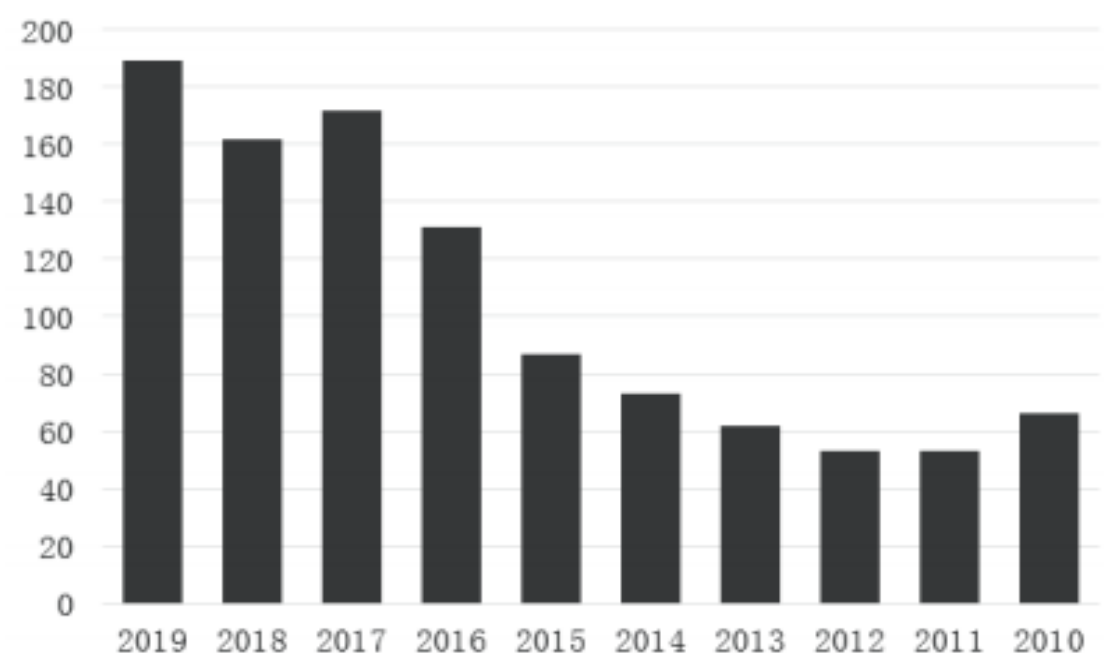

Figure 1: Ten Years studies in Web of Science and Google Scholar on Al \& Education (Chen, Chen \& Lin, 2020)

Fryer et al., (2017) also found that social robots (such as chat robots) and human learning partners have the same effect on stimulating and maintaining students' interest in language learning. An intelligent robot can be not only a learning partner of students but also a tutor for students. Robot tutors have a friendly interaction and consolation effects and can be used as cognitive tools for children with autism spectrum disorders and personalised learning tutors for children with hearing and language impairment (Broadbent et al., 2018). Koedinger and Aleven, (2015) found that although the intelligent tutoring system can significantly improve students' academic performance, cultivating students' ability to analyse and solve problems is still a challenge for the intelligent tutoring system. According to the research of Frey and Osborne (2017), routine and easily defined types of work are most likely to be replaced. In other words, tasks that are repetitive necessitate a lot of data analysis and precise positioning will be replaced by Al. The research on learning science is associated with students' behaviour in the system that is beneficial for the modified system, which may be more appropriate and effective for students (Boveja, \& Angely, 2008). As education grows, researchers are trying to apply advanced Al techniques such as deep learning, data mining to deal with complex issues and customize teaching method for individual student. Despite growing research in the area most researchers are subjected to the personal preference in the area of EAI and lack of studies on bibliometric analysis in the EAI research field created a gap in the study. Purpose and Research question are;

The purpose of this study is to explore EAl, using the bibliometric analysis method that facilitates in evaluating the research development comprehensively and methodically. Concentrating on EAl, this study aims at addressing the following research questions (RQ):

RQ1: What are the main keywords in EAI research?

RQ2: What are the main clusters in EAI research?

RQ3: What is the core topics based on the results of keywords and clusters analysis?

The scope of this study is to answers the research questions will help in understanding the EAI research field completely with the help of the bibliometric method. In particular, Citespace software will be used for analysing the Scopus-web of science and Google Scholar published 
articles on EAI. The findings of these analyses will probably contribute appropriate insights into the contemporary state of EAI research from multidimensional perspectives besides establishing the basis for other studies in a similar field. Furthermore, this study's findings will serve as empirical evidence that can complement conventional literature.

\section{Method}

\subsection{Data collection}

The bibliometric analysis data were collected from three common sources; Scopus, Web of Science and Google Scholar. Data collected from these databases could be well recognised by the selected analytical tools, while date collected from other databases, such as IEEExplore or Engineering Village, are not well organised (Dalpé, 2002). Scopus was confirmed as a retrieval source due to its nature of abundant reference and compatibility with the analysis tools of CiteSpace. The search terms included Topic Search (TS) = "Al" OR "Artificial Intelligence*" or "Machine Intelligence*" or "Machine Learning*" or "Deep Learning*" or "Deep Networks" or "Intelligent Tutoring System*") AND ("Education*" or "Pedagogy*" or "Learning*"). The retrieval period was set from 2000 to 2020 and the download date of data retrieval was July 17, 2020. A total of 8,660 pieces of data were finally retrieved.

\subsection{Data analysis}

The bibliometric analysis methods were adopted due to three reasons. Firstly, bibliometric analysis can process enormous data accurately within a short span of time with the help of computer algorithms. Secondly, bibliometric analysis is capable of providing more detailed information, including keywords and clusters. Thirdly, bibliometric analysis tools, such as CiteSpace, help readers in comprehending the whole development in the research field. CiteSpace, adopted tool, is software that is specifically designed for bibliometric analysis. It provides various functions for visualising network patterns, enabling the researcher to create visualisation figures that show a pattern from diverse distribution via keywords analysis and cluster analysis (Chen, 2006).

Specifically, this research conducted a keyword analysis and a cluster analysis using CiteSpace software in the beginning. Based on the outcomes of the two analyses, the core topics of EAI research were then identified and in-depth discussions about related research were carried out. Notably, specific keywords reflect the idea and research trend of an article which can be effectively determined through the keyword co-occurrence analysis. In this analysis, each keyword serves as a node, whereas an association between two keywords establishes a keyword cooccurrence.

CiteSpace visualised keyword co-occurrence in terms of keywords frequency and how the keywords are identical. In this case, keywords with high frequency suggest the core topics of interest in EAI research. Admittedly, keyword analysis can reveal the core topics of the research, but it is unable to identify which literature has contributed to them. Therefore, this research conducted a literature cluster analysis. In addition, the results from keyword analysis and cluster analysis would make the identification of core topics more accurate and rigorous. A cluster analysis carried out notably with the help of CiteSpace is able to outline fundamental research domains in a specific area of study (García-Lillo, 2009).

The CiteSpace software was run by selecting the Reference for Cluster analysis where the threshold parameters (citation, co-citation and cosine coefficient thresholds) were set as 2; $2 ; 30,4 ; 330,4 ; 3 ; 25$ mentioning to the start, middle and end of a chosen period respectively. The terms taken out from co-citation literature were grouped into numerous clusters utilising a 
log-likelihood ratio algorithm (Small, 1973). Ultimately, each core cluster included terms with similar characteristics which are significantly related to each other. In this study, the importance of a specific cluster for representing a core EAl topic was calculated on the basis of its silhouette value or consistency of terms with the help of a range of -1 to +1 , where 1-value denotes an ideal solution. The clusters have a silhouette value larger than 0.8 were perceived to be superior clusters.

As mentioned earlier, based on the results of the keyword analysis and cluster analysis, this research identified the core issues that EAI research focused on. As such, the core issues were analysed by quantitative as well as qualitative methods. First of all, the cluster analysis feature of CiteSpace software was used for determining the core literature. Secondly, additional text analysis about the core literature was performed, further confirming or supplementing the findings of the above quantitative methods. Thirdly, identified core topics were categorised into three aspects:

a. The influence of Al application on students learning

b. The relationship between teachers and machines

c. The advantages and disadvantages of Al algorithms in education.

\section{RESULTS}

\subsection{The main keywords}

Figure 2 indicated that the co-occurring of the keyword network which reflects an overview of EAI research. In this case, a corresponding keyword is identified as the centre of each node, whereas cross-shaped nodes represent the dispersion of related keywords. Fundamentally, the relationship between the thickness of cross-shaped nodes and the number of publications is comparable. Overall, a large proportion of these keywords appeared to be closely linked. The obtained results reveal the following core keywords in EAl research are: "Al", "education", "learning system", "student", "teaching", "engineering education", "computer-aided instruction", "machine learning", "education computing", and "e-learning". The keyword co-occurrence analysis, the identified main keywords in research provide a good understanding of the literature's pivotal terms and contents (Xiang, Wang \& Liu 2017).

In other words, these identified keywords are the most popular subjects in EAI. From these keywords, it can be found that EAI research focuses on Al applications (e.g. learning systems, computer-assisted teaching), students learning (e.g. students and active learning), the relationship between teacher and computers (e.g. computer-aided instruction), educational information (e.g. education computing, e-learning) and Al algorithms (e.g. machine learning). In the field of EAl, students and teachers are the core objects of concern because the service objects of artificial intelligence applications are primarily students and teachers and the teaching work of teachers is also student-centred. At the same time, the development and use of algorithms and artificial intelligence applications must be based on the understanding of educational concepts and objects. Therefore, fundamentally speaking, the utilisation of Al technology in the field of education does not encounter a technical problem; rather it is an educational issue. 


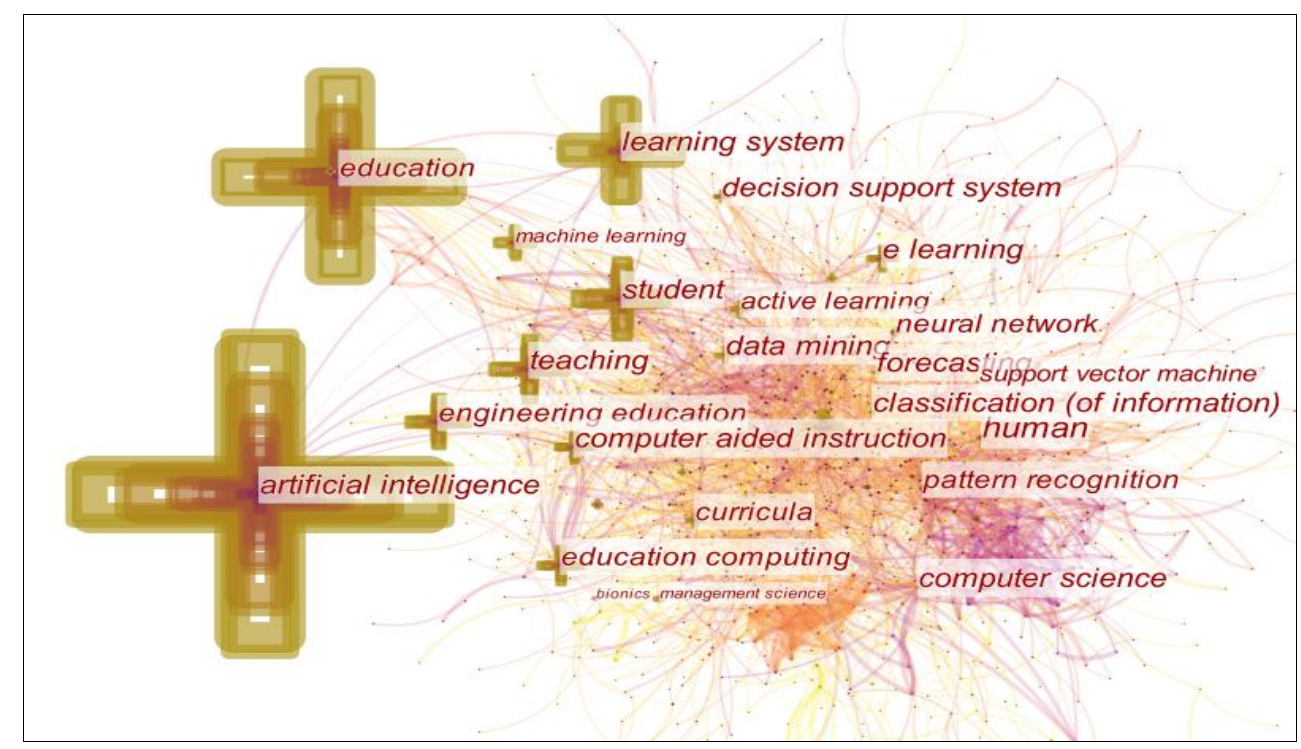

FIGURE 2: Co-occurring keyword network in EAI research

\subsection{The main clusters}

Table 1 lists the five most important and meaningful clusters in EAI research; cluster 0 (intelligent tutoring system), cluster 1 (learning system), cluster 2 (student), Cluster 4 (labelled training data) and cluster 5 (pedagogy). The silhouette values of all the five clusters are over 0.85 , indicating their reliability. Taking into consideration the main terms of these clusters, they can be classified into three aspects: intelligent applications (e.g. intelligent tutoring system and learning system), student learning and teaching methods (e.g. active learning, flipped classroom and distance education) and Al algorithm (e.g. deep learning, decision tree, Markov process, semi-supervised learning and feature space). Further text analysis of the relevant literature in the five clusters shows that the research on Al applications primarily discusses the influence of Al applications on education. Like the automatic scoring system, it can assist teachers in evaluating students' learning efficiency and the students can learn through intelligent tutoring system. In terms of students' learning and teaching methods, it primarily focuses on the effects of intelligent application and teaching methods on students' learning. In other words, it explores the relationship between students or teachers and machines. Regarding the Internet and virtual community, Al relies on making students' learning ubiquitous; intelligent education application can help teachers record and monitor learners' learning behaviours besides conducting intelligent analysis on their learning characteristics and learning styles with the purpose of providing suitable learning content, method and mode in order to realise the individualisation of students' learning. Finally, the Al algorithm research fundamentally focuses on the applicability of the algorithm. For instance, algorithms and big data improve the effectiveness and accuracy of education services, but some scholars believed that relying heavily on algorithms is very dangerous (Jain, 2017). 
Table I: The top five clusters

\begin{tabular}{|c|c|c|c|c|}
\hline Cluster ID & Size & Silhouette & Cluster Label & Main Terms (LLR) \\
\hline 0 & 70 & 0.956 & $\begin{array}{l}\text { Intelligent } \\
\text { tutoring } \\
\text { system }\end{array}$ & $\begin{array}{l}\text { Intelligent } \\
\text { system, authoring tool, computer- } \\
\text { aided instruction, example tracing } \\
\text { tutor }\end{array}$ \\
\hline 1 & 70 & 0.870 & $\begin{array}{l}\text { Learning } \\
\text { system }\end{array}$ & $\begin{array}{l}\text { Learning system, Deep learning, } \\
\text { Decision tree, Markov process }\end{array}$ \\
\hline 2 & 69 & 0.910 & Student & $\begin{array}{l}\text { Student, engineering } \\
\text { education, automated } \\
\text { active learning }\end{array}$ \\
\hline 3 & 48 & 0.947 & $\begin{array}{l}\text { Labelled } \\
\text { training data }\end{array}$ & $\begin{array}{l}\text { Labelled training data, semi- } \\
\text { supervised learning, feature space }\end{array}$ \\
\hline 4 & 45 & 0.959 & Pedagogy & $\begin{array}{l}\text { Pedagogy, teaching } \\
\text { strategy, flipped } \\
\text { classroom, distance education }\end{array}$ \\
\hline
\end{tabular}

\subsection{The three core topics}

Evidence from the keyword analysis and cluster analysis shows that the current EAl research mostly revolves around five aspects: Al applications, human-computer relations, Al algorithms, students' learning and educational informatisation. Integrating the analysis of relevant literature into the cluster analysis reveals that the current EAI research fundamentally focuses on three core topics:

a. The influence of Al application on students' learning

b. The relationship between teachers and machines

c. The contribution and risks of algorithms in education

\section{DISCUSSION}

\subsection{The influence of Al application on students' learning}

The analysis of the relevant literature has revealed that there are different views about the effect of Al application on students' learning. A number of studies have proved that Al applications can significantly improve students' learning effect. Edwards et al., (2018) believed that practising the social robots in the classroom is capable of promoting personalised learning of the students while changing the traditional classroom and teacher-student relationship. Furthermore, the teachers' role will be transformed into a supervisor. The current intelligent educational robot also faces some severe challenges that entail the difficulty in realising automatic social interaction, the development of automatic speech recognition and social signal processing have not yet met the needs of practical application, computer vision has limited ability to deal with common problems in education and home environments and the number of social behaviours of robots does not improve the learning effect (Broadbent et al., 2018). Another critical Al application is intelligent 
tutoring system. Different intelligent tutoring systems impact students' learning. This impact is affected by age, curriculum, discipline and learning strategies. As a computer-assisted teaching method, an intelligent tutoring system can significantly improve students' mathematics scores and the effect of personalised teaching and reduce the education cost of middle school and high school (Barrow, Markman \& Rouse, 2009). As far as the effectiveness is concerned, although an intelligent tutoring system is at par with human tutoring in improving STEM learning ability of the students, it should not be used as a substitute for the entire teaching situation, but as a substitute for students' classroom and after-school work (Vanlehn, 2011). It is worth noting that the improvement in students' learning effects by an intelligent tutoring system may not be immediate. A study spanning over two years involving the students of the middle school revealed that the intelligent tutoring system has not impacted learning algebra by middle school students in the first year, but has a positive effect in the second year (Walker, Rummel \& Koedinger, 2014).

Al application empowers teaching methods and further promotes students' learning effect. For example, inverted classroom adopted the technology (such as intelligent tutoring system and online learning systems) with the purpose of moving lectures from classroom to the open environment as well as employed practical learning activities that can be carried out in the classroom (Bailey, 2019). Thanks to the implementation of diverse technological developments, the conventional classroom setting has nothing to do with the teaching as well as learning environment. Contrary to the traditional classroom setting, this particular kind of blended learning classroom bestows student an opportunity of active participation coupled with problem-based learning (Strayer, 2012; Mason, Shuman \& Cook, 2013). Al applications also impact the utilisation of active learning. Through teachable agents, the students can experience more active and constructivist learning and apply their metacognitive strategies in a novel learning environment (Leelawong \& Biswas, 2008; Dzikovska et al., 2014; Pareto \& Lena 2014). The application of active learning has resulted in improvement in the average test scores by about $6 \%$ and reduction in the probability of failure by 1.5 times among the students in relation to the adoption of conventional structure of delivering lecture (Freeman et al., 2014; Frey \& Osborne, 2017). It can be seen from the above that although the Al application has shown the great value and potential in improving students' learning effect, this positive effect is primarily reflected at students' cognitive level; language learning, mathematics scores, STEM learning, Algebra Learning and academic performance. Perceptibly, the current Al application is still at the stage of weak Al and achieving personalised and intelligent high-quality learning is really challenging. It plays a limited role in promoting students' non-cognitive ability, problem-solving ability, innovation ability and comprehensive quality. In addition, although the current Al application in the process of insight, analysis and guidance of students' growth and development can better understand the characteristics of students than teachers, but this may also lead to teachers' excessive dependence on the Al application in the process of student education. The more teachers rely on the Al application, the more likely they will lose their ability of judgment, thinking and innovation. Therefore, how teachers view the relationship between themselves and machines is another critical issue in EAl research.

\subsection{The relationship between teachers and machines}

Whether Al can replace teachers is the current theme in the area of EAl research. The advent of the Al era has brought enormous challenges to the value of teachers.

As far as the teachers' work is concerned, Al's absolute advantage in the rapid storage and transmission of massive knowledge is beyond human teachers. In this case, teachers who only 
impart knowledge will be replaced. At the same time, Al can provide the best education in the future because it can provide targeted and personalised education to the students according to their diverse interests and characteristics (Nye, 2014). However, it is intricate for human teachers to teach students in accordance with their aptitude in the context of class teaching system because they are not able to pay heed to every student. From the perspective of costeffectiveness, Al can replace some of the work of teachers, meaning that to a certain extent, Al can solve the problem of shortage of teachers (Edwards \& Cheok, 2018). Many studies have confirmed that Al applications (such as robots and intelligent tutoring systems) can replace some of the teachers' tasks. Cheng et al., (2018) believed that robots could assist teachers in pre-class preparation, classroom inspections and after-class auxiliary services. It can also support distance learning by providing learners virtual learning environments and one-on-one tutoring. Its service objects include kids, students of the primary and secondary schools, students of the colleges, adults and elderly. Mubin et al., (2013) believed that robots could assume the role of tutors in the education process, fundamentally used for language development and acquisition, science education, technology and computer programming. Zhang et al.,(2011) proposed teaching robots, emphasising that teaching robots are robots that can perform duties of teachers in various applications.

However, the task of teachers should acquire the ability to control technology rather than the ability controlled by technology. Al will not be replacing teachers; rather it will be replacing traditional teaching methods (Selwyn, 2019). In other words, Al will replace those who cannot be innovative in teaching models in the context of Al technology. Although Al can help teachers better understand and teach students, it cannot entirely replace the environment of the classroom. The classroom is not meant only to convey knowledge and skills but also to develop social learning of the students and shape their cultural awareness as well as social values. Moreover, according to Kolchenko, (2018), Al applications rely heavily on the quality and quantity of data. If the collected data is limited and damaged, the positive effects of Al applications will be minimal and may even be harmful. At the same time, high-quality data undoubtedly comes from active and persistent high-achieving students. The decisions or suggestions made by Al systems based on these data are more appropriate for high-achieving students. This will exacerbate the unfairness between high- and low-achieving students. Therefore, experienced and innovative teachers will not be replaced because they can understand students and teaching situations well.

As a matter of fact, the value orientation of Al applications' design and development should be people-oriented, serving people's will and expectations. In this case, some Al authoring tools are dedicated to stimulating teachers' initiative and innovation in the use of Al (Bakki et al., 2018). The authoring tool solved the issue of knowledge requirements for designing or developing Al applications, especially for the teachers who lack expertise in information technology tools, thereby reducing the total cost involving Al application design and technical requirements. For example, scikit-learn is a Python module that integrates various modern machine learning algorithms that are dedicated to offering machine learning to amateur utilising sophisticated languages (Pedregosa et al., 2013). This type of software package is an education-oriented tool that can stimulate teachers' enthusiasm and creativity while reducing the technical difficulty of teachers using Al. Another type of authoring tool is an example-tracing tutor built with the help of drag-and-drop technology which evaluates students' behaviour by flexibly comparing students with correct and incorrect problem-solving examples (Aleven et al., 2009). Hence, consideration of creating Al application by oneself without programming was a new trend of the human-machine collaboration relationship. 


\subsection{The contribution and risks of Al algorithm in education}

The algorithms are not only the soul of $\mathrm{Al}$ but also the critical element of $\mathrm{Al}$ to realise intelligent behaviour. Among them, deep learning has the most far-reaching influence. It has made essential contributions in theory (such as information theory and decision theory), algorithm (such as decision tree, naive Bayes classification and ordinary least squares regression) as well as intelligent applications (such as computer-aided instruction and robot education products) (Lecun, Bengio \& Hinton 2015). Al algorithms directly promote the development of visual object recognition, target object detection and speech recognition. They also make the application of intelligent education change from "not available and strenuous" to "easy to use". The algorithms are extensively used in education. They are used for calculating students' knowledge stock, subject tendency, thinking type, emotional preference and ability potential besides pushing students' personalised courses, learning resources, learning suggestions and learning strategies in addition to analysing and evaluating teachers' teaching performance, self-regulation, monitoring teaching activities and making decisions regarding the future development and daily operation of schools ( $\mathrm{Wu}$ et al., 2008; Pasquinelli, 2019). However, the risks brought by algorithms have also attracted the attention of many scholars. First of all, algorithms cannot understand the system and the complexity of education. The essence of algorithms and computational models is the simplification. No algorithm or model can cover all the complex factors of the real world or all the nuances of human communication. The mathematical functions that form an algorithm cannot contain all of its calculations. At most, mathematics only describes certain processes of nature, but its symbols do not include everything (Jordan \& Mitchell, 2015). The algorithm's quantification and simplification of educational objects and educational processes make education lose its rich connotation and valuable components, such as tacit knowledge that cannot be quantified and the teachers' role model.

Secondly, black boxes are the potential danger of algorithms. Between the input data and the output result of the algorithm, there is a black box that cannot be discerned. It means that the user cannot understand the algorithm and why it produces results in the EAI domain. On the one hand, it is difficult for users and designers to explain the algorithm's entire operation. On the other hand, machine learning algorithms enable machines to have their own learning capabilities and their self-learning and self-training based on big data sets are unknown (Jordan \& Mitchell, 2015). In other words, the algorithms can deeply understand teachers and students, but they cannot understand the logic and reasons why algorithms deal with educational problems (Luke, 2015). Therefore, teachers cannot judge whether the decisions they make based on the algorithms are correct and whether they will harm students' growth. This may cause education to lose its own freedom and democracy in the EAl field.

Finally, excessive reliance on algorithms may cause teachers to lose their educational wisdom. The application of algorithms or Al in education is primarily an educational issue. From the perspective of algorithm design or development, the educational philosophy and values that designers have directly determine what kind of data they collect and what kind of algorithm or application they develop. If the designer lacks relevant educational theoretical knowledge, the algorithm itself is likely to be implanted with wrong ideas or values. Teachers' decisions or judgments regarding this type of algorithm are likely to be wrong or even harmful for the students. From the perspective of teachers, teachers rely too much on the decisions made by algorithms without thinking, which, to a large extent, leads to the loss of opportunities for thinking and innovation, the loss of insight and creativity in the classroom and the loss of practical wisdom or 
knowledge. In this case, the teaching profession' s disappearance is not due to $\mathrm{Al}$, but the teachers themselves if they overuse $\mathrm{Al}$ and lose their educational wisdom.

It can be seen from the above that the application of algorithms in education is a coexistence of opportunities and crises which are fundamentally educational and ethical issues. The development and use of algorithms must explicitly embed human-oriented values in the algorithm code to create a big data model that meets educational needs and ethical standards. The principles of UNESCO's humanistic Al application include four specific aspects:

1) The development of Al should be controlled by humans and should be human-oriented

2) The deployment of Al should serve humans and should be aimed at enhancing human abilities

3) The design of Al should be ethical, avoid discrimination, fair, transparent and auditable

4) The impact of Al on people and society should be monitored and evaluated during the entire value chain (UNESCO, 2019).

Therefore, educators should have a clear understanding of the contribution and risks brought by the algorithm and they should manage the educational Al application in accordance with the human-oriented principle so that the algorithm can serve the development of students and teachers in the EAI field.

\subsection{Conclusion}

The development of EAl has partly modified the unadventurous learning structure as well as the results of intelligence and learning, propelling the emphasis of the present study in evaluating the fundamental topics of the amalgamation amid Al and education. Based on the keywords and clusters analysis results, this study provided essential insights into core topics in EAI research from 2000 to 2020. The core topics of EAl research focus on three aspects:

a. The influence of Al application on students' learning

b. The relationship between teachers and machines

c. The contribution and risks of Al algorithms in education.

First of all, Al applications can improve the effectiveness of students' learning, but this positive effect must take the students' centres and students' diversity with different levels of motivation, attitudes and responses into account. Secondly, although Al can replace part of the teachers' work, the relationship between the teacher and the machine should be cooperation, not the relationship between replacement and being replaced, under the premise that teachers give full play to their initiative and innovation. It is encouraging that authoring tools can serve nontechnical professionals who can use tools to create their own Al applications to assist teaching. Finally, algorithms are the soul of $\mathrm{Al}$ and their applications in education are extensive and understand teachers and students thoroughly. However, it also has high risks, because algorithms cannot understand the system and complexity of education. Therefore, it is necessary not only to give full attention to the value and role of $\mathrm{Al}$ in the field of education but also to recognise and control the adverse effects and dangers it brings.

There is no systematic research on the far-reaching impact of Al applications on education. Future research may deal with the tracking investigation of Al use effects on learning results, learning practices and new learning methods. The lack of empirical research on how to realise the 
collaborative relationship between teachers and machines and its effect evaluation, imminent research might emphasise the realisation mechanism of the collaborative relationship between teachers and machines. In fact, Al technology is one of the components of the mechanism. Besides, as far as the Al algorithm is concerned, how to play the value and role of the algorithms in education, control the risk brought by it and stimulate the initiative and innovation of teachers may be one of the focuses of future research. This study is not free of limitations. Scopus is one of the most significant bibliographic databases worldwide, but it may cover small quality of articles. In addition, CiteSpace software has some special requirements for data format that affects the scope of data collection as well as analysis. Future research may continue to gain more in-depth insights from various aspects by using other search engines.

Conflict of Interest: There is not conflict of interest among the authors.

\section{References}

Aleven, V., Mclaren, B., Sewall, J., \& Koedinger, R. (2009). A new paradigm for intelligent tutoring systems: example-tracing tutors.International Journal of Al in Education, 19(2), 105-154. https://doi.org/10.1007/s11825-010-0238-8.

Bailey, L. W. (2019). New Technology for the Classroom: Mobile Devices, Artificial Intelligence, Tutoring Systems, and Robotics. In Educational Technology and the New World of Persistent Learning, 111. IGI Globa.

Bakki, A., Oubahssi, L., George, S., \& Cherkaoui, C. (2018). MOOCAT: A visual authoring tool in the cMOOC context. Education and Information Technologies. doi:10.1007/s10639-018-9807-2.

Barrow, L., Markman,L.\& Rouse,E.(2009).Technology's edge: The educational benefits of computer-aided instruction. Social Science Electronic Publishing, 1(1), 52-74. doi.org/10.1257/pol.1.1.52.

Belpaeme, T., Kennedy, J., Ramachandran, A., Scassellati, B., \& Tanaka, F. (2018). Social robots for education: A review. Science Robotics, 3(21), eaat5954.doi:10.1126/scirobotics.aat5954.

Boveja, R. ,\& Angely, W. (2008). Why students engage in "gaming the system. Journal of Interactive Learning Research,19(Suppl 1), 185-224. https://doi.org/10.1249/01. .MSS.0000402463.77363.8b.

Broadbent, E., Feerst, D. A., Lee, S. H., Robinson, H., Albo-Canals, J., Ahn, H. S., \& MacDonald, B. A. (2018). How Could Companion Robots Be Useful in Rural Schools? International Journal of Social Robotics, 10(3), 295-307.doi:10.1007/s12369-017-0460-5.

Chen, L., Chen, P., \& Lin, Z. (2020). Artificial intelligence in education: a review. leee Access, 8, 7526475278. DOI: 10.1109/ACCESS.2020.2988510

Chen, M.(2006). Citespace II: detecting and visualizing emerging trends and transient patterns in scientific literature. J. Am. Soc. Inf. Sci. Technol. 57 (3), 359-377. https://doi.o rg/10.1002/asi.20317.

Cheng, Y.-W., Sun, P.-C., \& Chen, N.-S. (2018). The essential applications of educational robot: Requirement analysis from the perspectives of experts, researchers and instructors. Computers \& Education, 126, 399-416.doi:10.1016/j.compedu.2018.07.020 .

Edwards, B. I., \& Cheok, A. D. (2018). Why Not Robot Teachers: Artificial Intelligence for Addressing Teacher Shortage. Applied Artificial Intelligence, 1-16. doi:10.1080/08839514.2018.1464286

Edwards, C., Edwards, A., Spence, P. R., \& Lin, X. (2018). I, teacher: using artificial intelligence (AI) and social robots in communication and instruction. Communication Education, 67(4), 473480.doi:10.1080/03634523.2018.150 
Freeman, S., Eddy, L., Mcdonough, M., Smith, M. K., Okoroafor, N., \& Jordt, H., et al. (2014). Active learning increases student performance in science, engineering, and mathematics. Proceedings of the National Academy of Sciences of the United States of America, 111(23), 8410-8415. https://doi.org/10.1073/pnas.1319030111.

Frey, C. B., \& Osborne, M. A. (2017). The future of employment: How susceptible are jobs to computerisation? Technological Forecasting and Social Change, 114, 254-280. doi:10.1016/j.techfore.2016.08.019.

Fryer, L. K., Ainley, M., Thompson, A., Gibson, A., \& Sherlock, Z. (2017). Stimulating and sustaining interest in a language course: An experimental comparison of Chatbot and Human task partners. Computers in Human Behavior, 75, 461-468.doi:10.1016/j.chb.2017.05.045

García-Lillo, F., Úbeda-García, M., \& Marco-Lajara, B. (2016). The intellectual structure of research in hospitality management: A literature review using bibliometric methods of the journal International Journal of Hospitality Management. International Journal of Hospitality Management, 52, 121-130 .org/10.1016/j.ijhm.2015.10.007.

Guilherme, A. (2017). Al and education: the importance of teacher and student relations. AI \& SOCIETY, 34 (1) , 47-54.doi:10.1007/s00146-017-0693-8.

Han, J., Zhao, W., Jiang, Q., Oubibi, M., \& Hu, X. (2019, October). Intelligent Tutoring System Trends 20062018: A Literature Review. In 2019 Eighth International Conference on Educational Innovation through Technology (EITT) (pp. 153-159). IEEE. doi:10.1109/eitt.2019.00037.

Jain, A. (2017). Weapons of Math Destruction: How Big Data Increases Inequality and Threatens Democracy. Business Economics, 52(2), 123-125.doi:10.1057/s11369-017-0027-3.

Jordan, M. I., \& Mitchell, T. M. (2015). Machine learning: Trends, perspectives, and prospects. Science, 349(6245), 255-260. doi:10.1126/science.aaa8415.

Kandlhofer, M., Steinbauer, G., Hirschmugl-Gaisch, S., \& Huber, P. (2016, October). Artificial intelligence and computer science in education: From kindergarten to university. In 2016 IEEE Frontiers in Education Conference (FIE) (pp. 1-9). IEEE. https://doi.org/10.IEEE.10.1109/FIE.2016.7757570.

Koedinger, K. R., \& Aleven, V. (2015). An Interview Reflection on "Intelligent Tutoring Goes to School in the Big City." International Journal of Artificial Intelligence in Education, 26(1), 1324.doi:10.1007/s40593-015-0082-8.

Kolchenko, (2018) "Can Modern Al replace teachers? Not so fast! Artificial Intelligence and Adaptive Learning: Personalized Education in the Al age," HAPS Educator, 22, (3), 249-252. doi:10.21692/haps.2018.032.

Lecun, Y., Bengio, Y., \& Hinton, G.(2015). Deep learning. Nature,521(7553), 436. http://doi.org/10.1142/S1793351X16500045.

Leelawong, K., \& Biswas, G. (2008). Designing learning by teaching agents: The Betty's Brain System. International Journal of Al in Education, 18(3), 181-208.

Luke Dormehl. (2015). The formula: how algorithms solve all our problems. and create more. perigee books.

Mason, S. , Shuman, R. , \& Cook, E.(2013). Comparing the effectiveness of an inverted classroom to a traditional classroom in an upper-division engineering course. IEEE Transactions on Education, 56(4), 430-435. http://doi.org/10.1109/TE.2013.2249066.

Mubin, O., Stevens, C. J., Shahid, S., Al Mahmud, A., \& Dong, J. J. (2013). A review of the applicability of robots in education. Journal of Technology in Education and Learning, 1(209-0015), 13. 
Nye, D. (2014). Intelligent Tutoring Systems by and for the Developing World: A Review of Trends and Approaches for Educational Technology in a Global Context. International Journal of Artificial Intelligence in Education, 25(2), 177-203.doi:10.1007/s40593-014-0028-6.

Pareto, \& Lena. (2014). A teachable agent game engaging primary school children to learn arithmetic concepts and reasoning. International Journal of Al in Education, 24(3), 251-283. Retrieved from https://link .springer.com/article/10.1007/s40593-014-0018-8.

Pasquinelli, Matteo. (2019) How a Machine Learns and Fails: A Grammar of Error for Artificial Intelligence. Spheres, Journal for Digital Cultures, 5 : 1-17.

Pedregosa, F., Gramfort, A., Michel, V., Thirion, B., Grisel, O., \& Blondel, M., et al. (2013). Scikit-learn: machine learning in python. Journal of Machine Learning Research, 12(10), 2825-2830. Retrieved from https://dl.acm.org/citation.cfm?id=2078195.

Politis, D., Kyriafinis, G., \& Aidona, S. (2018). Al assisted multimedia learning protocols: the cases of special education for the impaired in hearing and music learning for chanting. Int Rob Auto J, 4(4), 263-264.doi: 10.15406/iratj.2018.04.00134.

Roll, I., \& Wylie, R. (2016). Evolution and revolution in artificial intelligence in education. International Journal of Artificial Intelligence in Education, 26(2), 582-599. DOI 10.1007/s40593-016-0110-3

Sales, A. (2019). Corporate Social Responsibility and Corporate Change. Springer International Publishing.doi:10.1007/978-3-030-15407-3.

Selwyn, N. (2019) Should Robots Replace Teachers? Al and the future of education. Cambridge: Polity Press.

Small, H. (1973). Co-citation in the scientific literature: A new measure of the relationship between two documents. Journal of the American Society for Information Science, 24 (4), 265269. doi:10.1002/asi.4630240406.

Song, P., \& Wang, X. (2020). A bibliometric analysis of worldwide educational artificial intelligence research development in recent twenty years. Asia Pacific Education Review, 21(3), 473-486. https://doi.org/10.1007/s12564-020-09640-2

Strayer, F. (2012). How learning in an inverted classroom influences cooperation, innovation and task orientation. Learning Environments Research, 15(2), 171-193. https://doi.org/10.1007/s10984012-9108-4.

UNESCO. (2019, July 5). First ever consensus on Artificial Intelligence and Education published by UNESCO. Retrieved August 3, 2020, from https : //en.unesco.org/news/first-ever-consensus-artificialintelligence-and-education-published-unesco.

VanLehn, K. (2006). The behavior of tutoring systems. International journal of artificial intelligence in education, 16(3), 227-265. https://content.iospress.com/articles/international-journal-ofartificial-intelligence-in-education/jai16-3-02

Vanlehn, K.. (2011): The Relative Effectiveness of Human Tutoring, Intelligent Tutoring Systems, and Other Tutoring Systems. In Educational Psychologist 46 (4), 197-221. http://doi.org/ 10.1080/00461520.2011.611369.

Walker, E. , Rummel, N. , \& Koedinger, K. (2014). Adaptive intelligent support to improve peer tutoring in algebra. International Journal of Al in Education,24(1), 33-61. https://doi.org/10.1007/s40593013-0001-9.

Wu, X. , Kumar, V. , Quinlan, R. , Ghosh, J. , Yang, Q. , \& Motoda, H. , et al. (2008). Top 10 algorithms in data mining. Knowledge and Information Systems, 14(1), 1-37. ht tps://doi.org/10.1007/s10115007-0114-2. 
Xiang, C., Wang, Y., \& Liu, H. (2017). A scientometrics review on nonpoint source pollution research. Ecological Engineering, 99, 400-408. http://doi.org/10.1016/j.ecoleng.2016.11.028.

Zawacki-Richter, O., Marín, V. I., Bond, M., \& Gouverneur, F. (2019). Systematic review of research on artificial intelligence applications in higher education-where are the educators?. International Journal of Educational Technology in Higher Education, 16(1), 1-27. https://doi.org/10.1186/s41239-019-0171-0

Zhang, A., \& Yu, Z. (2011). Teacher Robot, a new concept of modern teaching. 2011 6th International Conference on Computer Science \& Education (ICCSE).doi:10.1109/iccse.2011.6028732. 